\section{Message delivered to the CAG membership, from Dr William Paterson, CAG Past President, at the 2008 Annual General Meeting at CDDW 2008 in Montreal, Quebec}

William G Paterson MD FRCPC

Past President, Canadian Association of Gastroenterology

Department of Medicine, Queen's University, Kingston, Ontario

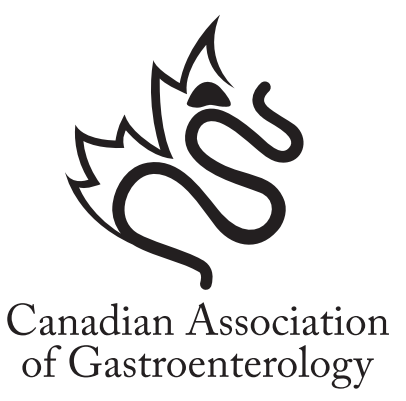

En français voir page 509
Tt is appropriate that my President's end of term message comes on the heels of Richard Fedorak's presentation, because it provides me with an opportunity to reinforce his message on the importance of our official foundation - the Canadian Digestive Health Foundation - to the future success of the Canadian Association of Gastroenterology (CAG).

The CAG is a vibrant organization that has been highly successful in providing research and educational opportunities to its membership. The research fellowship program is unparalleled in Canada. Our educational programs, whether delivered at the Canadian Digestive Diseases Week, via regional meetings or on our Web site, are also outstanding. More recently, we have expanded our role into public advocacy and have taken the lead in providing timely public responses to highly newsworthy gastroenterology (GI) issues. Because of the human resource initiative started by Des Leddin, we have been able to join the Wait Time Alliance and have had our wait time benchmarks formally accepted by the Canadian Medical Association. Despite these successes, we have a number of current and future challenges that need to be addressed. Just because we have joined the rather exclusive Wait Time Alliance club does not mean that we can now claim victory on wait times. For instance, the Ontario Ministry of Health's recent decision to freeze GI training positions in Ontario, despite us providing them with compelling data supporting the need to increase the number of gastroenterologists, shows that we still have a lot of work to do. In addition, the dramatic increase in demand for colonoscopy that is occurring as colorectal screening programs start up across the country will further challenge us to provide high-quality and timely care for patients with digestive illness. As professionals, we must avoid the urge to cherry pick in our practices, and remember that our primary role as gastroenterologists should be to help patients get better and not simply to rule out disease.

The generous financial support of our many industry partners has been integral to the success of our organization, and I would like to take this opportunity to formally thank our industry partners, who have taken what I believe in many instances to be a very altruistic approach to funding GI research and education in Canada. However, times are changing and I think it is clear that, in the future, industry may be constrained in their ability to provide the financial support they would like to give us and that we have been accustomed to. In addition, the research mandate of the Canadian Institutes of Health Research has been expanded significantly in recent years without a comparable budget allocation, so basic and applied research in GI will continue to feel the pinch. Thus, it is critically important that we, the CAG membership, fully support the Canadian Digestive Health Foundation now. It is our foundation, which, if successful, will not only be able to provide sustained support for education and research in gastroenterology, but will serve as a public vehicle to promote the need for enhanced resources for digestive diseases in Canada.

My past four years on the CAG Executive have been challenging but very rewarding, and I want to take this opportunity to thank all the members of the CAG who have contributed to the success of this organization. The many hardworking members of the CAG Executive and Board have greatly facilitated my term as President - in particular, Des Leddin, Ron Bridges and Phil Sherman. Of course, the real key behind the success of our organization has been the outstanding staff in the CAG office - Karen Moritz, Louise Hope, Sandra Daniels and our invaluable executive director, Paul Sinclair. I would like to thank them for their excellent support in guiding me through my Presidency.

It is time to move to the last agenda item of our meeting, and I must say that although I have enjoyed my term as President immensely, I have been looking forward to this particular moment, when I get to pass the gavel into the extremely capable hands of Dr Ron Bridges. Please join me in welcoming the 42 nd President of the CAG.

The CAG is proud to acknowledge its Benefactor Corporate Sponsors:
Abbott Canada
AstraZeneca Canada Inc
Axcan Pharma Inc
Nycomed Canada Inc
Olympus Canada Inc
Pentax Canada Inc
Procter \& Gamble Pharmaceuticals
Schering Canada Inc 


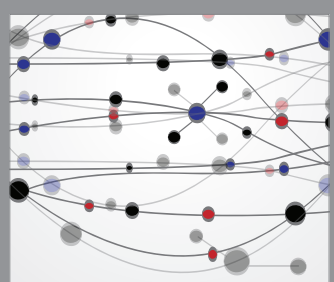

The Scientific World Journal
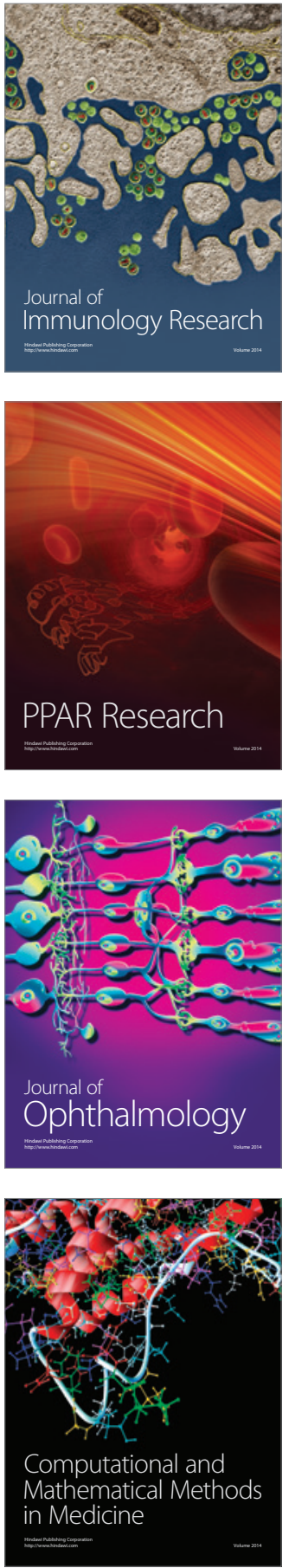

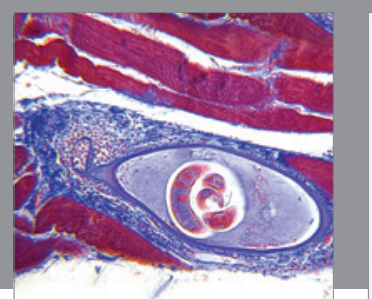

Gastroenterology Research and Practice

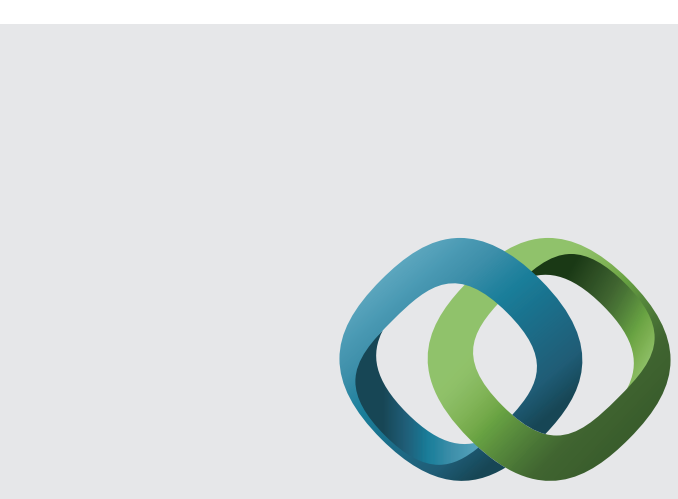

\section{Hindawi}

Submit your manuscripts at

http://www.hindawi.com
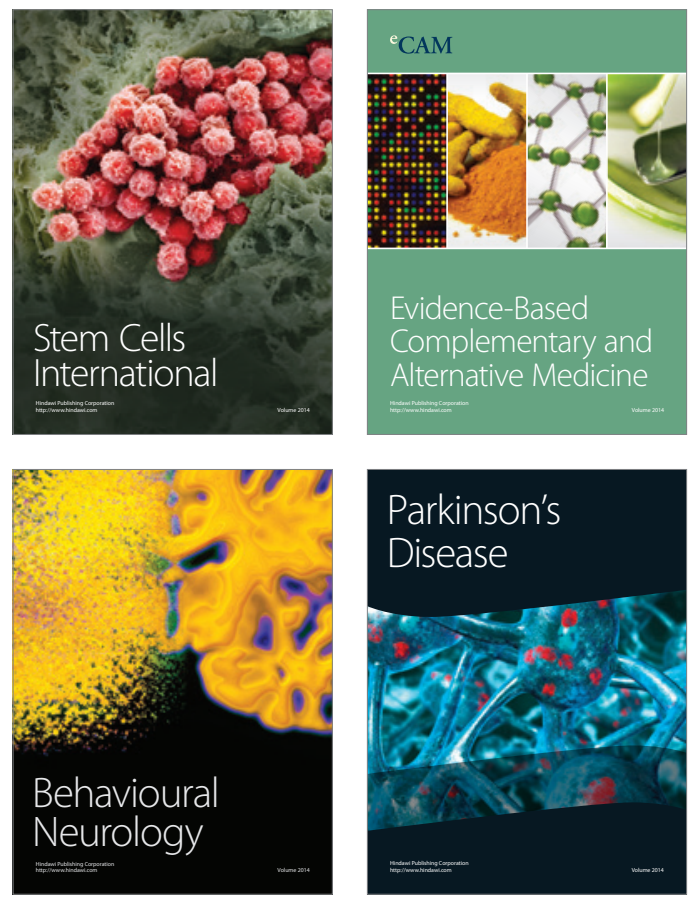
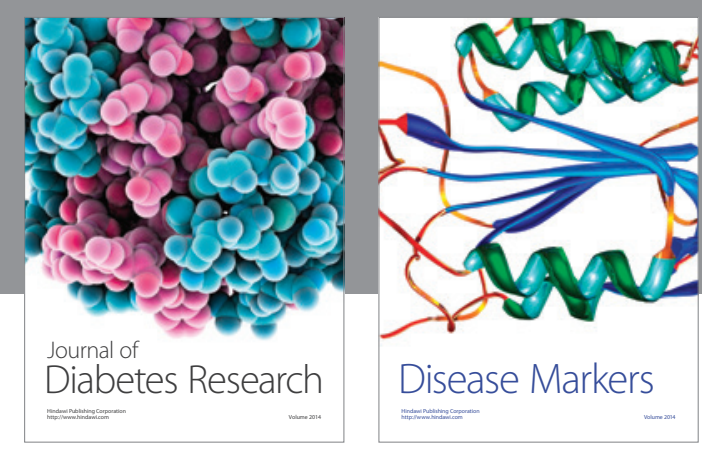

Disease Markers
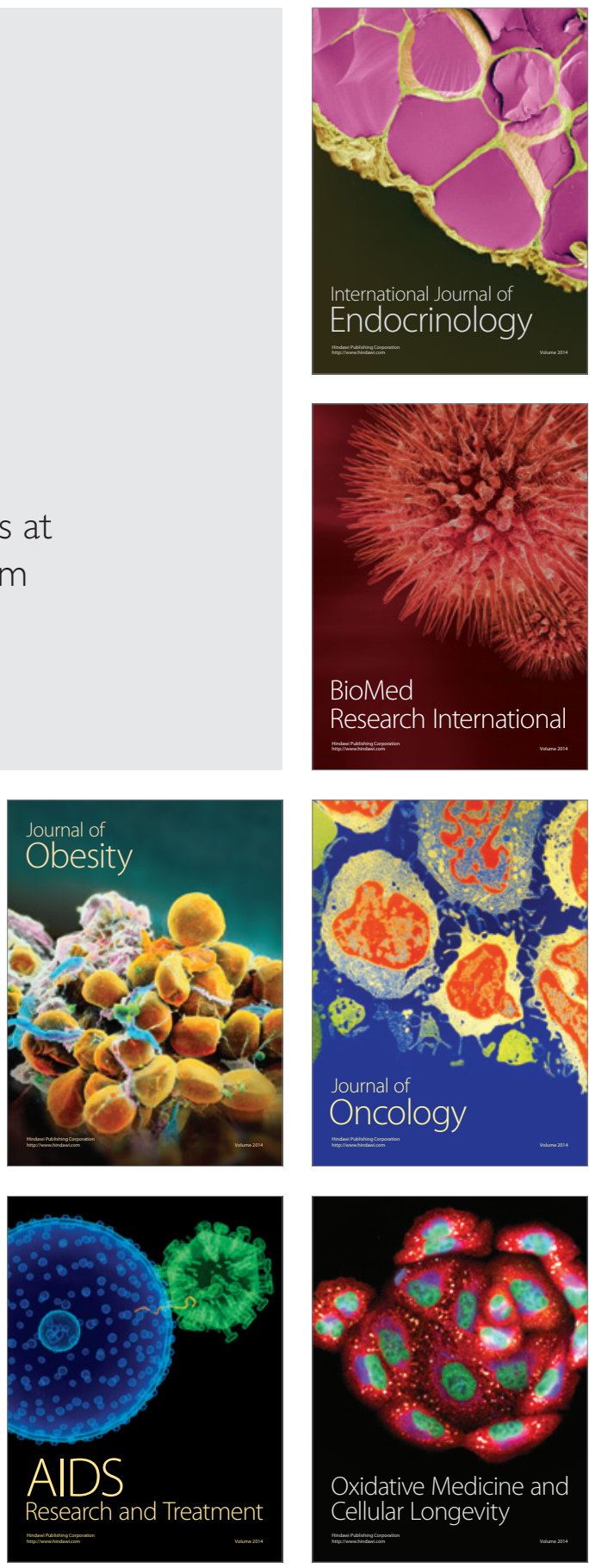